\title{
USE OF RADIO IN FOREST FIRE PROTECTION IN ONTARIO
}

\author{
By Peter McEwen, \\ District Forester, Sudbury
}

\begin{abstract}
The use of radio in fire protection practice in Ontario commenced in 1927. Development has mainly been in the northern and western districts where telephone line construction was more costly than in the older, settled districts. From 3 sets in 1927, radio equipment has been increased to 148 sets in 1940 . These are of different types according to use requirements. Simplicity of operation is essential because the operators are largely untrained, although interest on the part of tower observers and other users is increasing. Two way communication is made possible by the use of a small gasoline motor of commercial type for charging batteries. Installation in towers, methods of repairing and improving equipment, and the organization of "groups" of sets is described.
\end{abstract}

$\mathrm{T}$

HE SYSTEM of radio communication for forest fire protection in Ontario was started in 1927 under the direction of Mr. R. N. Johnston, to whom its inauguration and development in this Province can be largely credited. At that time, in the southern and eastern districts, the lookout tower system was fairly well started. Much of this country was sparsely settled and had roads and railroads along which telephone lines, of more or less permanency, had been or could be established between towers and fire ranging headquarters. A considerable mileage of tree telephone lines had also been built through the woods to towers, and existing rural telephone lines were usd. For these reasons the development of the use of radio has been for the most part in the northern and western districts.

The Sioux Lookout District in northwestern Ontario was chosen as the scene of the first trials as there was at that time no means of communication. The fire hazard was serious and, due to the rush of mining development and prospecting, was widely scattered and changing from place to place, presenting conditions of mobility with which radio is well suited to deal.

In 1927 three radio stations were started in Sioux Lookout District. The equipment at first allowed of communication by code only, except at points where electric power was available, when two-way voice transmission was possible. The number of stations gradually increased to about twelve in this district. Starting primarily as Forestry Stations for use during the summer months, they, at the same time, handled some public traffic and the demand made it possible and necessary to keep five or six stations open for public service the year round. The demand for commercial service as well as for Forestry purposes grew rapidly and in 1937 the Department of Lands and Forests co-operating with the Canadian Marconi Company inaugurated a system with stations at Red Lake, Pickle Lake, Sioux Lookout and Kenora, with three circuits on code and voice whereby anyone with the necessary equipment can connect with these stations and get long distance connection over the telephone system to any outside place. Many mines, hydro camps, log. ging camps, tourist out-fitters, and other organizations have rented sets suitable for speaking over these circuits and several aeroplanes are also equipped. While this semi-commercial system operated jointly by the Department and the Marconi Company has a wide and very reliable use in Fire Protection work in northwestern Ontario, it is chiefly with the portable five meter sets that this article is concerned. 
From 1927 to 1934 the number of radio stations steadily increased from 3 to 34 and during this period the technical details of the equipment changed very little, due largely to cost and lack of funds. About 1932-33 however the possibility of economically using ultra high frequencies was proved by laboratory tests, and apparatus for the use of these frequencies-on the general order of 5 meters or 60 megacycles-became available for general use. The possibilities of making use of these frequencies for instruments to be used in look. out towers was realized and in 1933 a five meter set was built and tested. While this instrument gave promise it was not considered good enough to put into service chiefly due to insufficient and unsatisfactory tubes. In 1934 a fairly good experimental set was constructed and tested. This set was sat. isfactory and this type of instrument is still being used, although improvements in design and parts have been made from time to time.

For the 1940 season the Province of Ontario will have in use 124 of these tower radio sets besides six sets specially built for use in trucks and boats and eighteen portable sets made for contacting fire fighting and work crews. Six of these are sets that work on a different wave length and were made up for experimental reasons, but twelve, developed this year, are of the same type as the tower sets but specially designed for lightness and portability. There is likely to be a wide demand for these, as it marks another stage in radio de. velopment with us-keeping remote work and fire crews in touch with towers and through them to headquarters.

The transmitting and receiving apparatus for the sets is contained in one unit which consists of a sheet metal box $91 / 4$ inches $\mathrm{x} 12$ inches $\times 15$ inches. Two shelves are attached to the front panel. The parts of the receiving apparatus are fastened to the lower shelf and the transmitting parts to the upper one. All parts are easily accessible from the rear or by removing the front panel, on the outside surface of which are the controls. A grip or handle for carrying is attached to the top panel of the box and a cable allows for plugging in to make connection with the batteries. The standard tower transmitter consists of a unity coupled oscillator operating in the region of 5 -meters and modulated by a class $\mathrm{B}$ audio amplifier. The receiver is of the conventional super-regenerative type, with pentode Radio Frequency stage. Part of the Audio System is used for both transmitter and receiver as a measure of operating economy.

The main point in which our sets differ from the commercial product is in the incorporation of a calling system. When the set is switched to stand-by position an incoming signal actuates a vacuum tube voltmeter which, through a series of relays, energizes a buzzer and signals the operator. $U p$ to the present this signal system has not proved entirely reliable and, therefore, "the stand-by" system, by which is meant that an operator in a tower can be called to the instrument as to a telephone, has not yet been brought to such perfection that it can be depended upon at all times and we still carry on the time schedule which will be explained later.

Power to operate the 150 watt generator charging the 6 volt storage bat. tery is provided by a small $5 / 8 \cdot \mathrm{HP}$ air cooled four-cycle gasoline motor of a commercial type such as is used for lighting systems of small summer cottages. As a rule this must be run about half an hour each day to keep the storage battery fully charged. A wind driven generator was used at first but was not entirely reliable. 
Primary power is furnished by a 6 volt storage battery driving a 350 volt genemotor for transmitter plate supply. Three $\mathrm{B}$ batteries and one $\mathrm{C}$ battery supply the receiver and audio system.

The antenna installation that appears to give the best results is of the half wave vertical type with quarter wave " $Q$ " bars, permitting long feeder lines without excessive losses.

A mast twelve feet long of dressed two by four tapered to one and three quarters inches square at the top is bolted to two iron brackets attached at a corner of the tower cabin and standing out enough to allow the mast to clear the eave. By removing the lower bracket bolt and allowing the light mast to revolve on the upper one, the antenna attached to the top of the mast can be swung down within reach of a square type cabin window for alteration or installation.

At the top of the mast an arm about three feet long is bolted through the mast at right angles to it and supported by a light brace. On this arm the antenna is fastened by means of insulating brackets.

The antenna consists of two L shaped aluminum tubes, each leg four feet long. Two of these are horizontal and parallel and are fastened to the arm about 3 inches apart by the insulating brackets. The other two extend vertically from the outer end of the arm, one up and one down. Wires hang from the inner or mast end of the antenna tubing and are led in through the cabin wall where they can be plugged to the set and grounded when not in use.

The height of the antenna above the earth averages about 90 feet and to this is added the height of the tower hill above the surrounding country. Under these conditions ranges of 30 to 35 miles are customary, although much longer ranges have proven satisfactory in many cases. Since waves of this frequency are semi-optical in nature, plenty of height at the antenna is essential for consistent low power communication.

A seat-box extending along one side of a square cabin or along three sections of an octagonal one, is provided to house the batteries, charging unit and hoisting tackle. The side and top of this box are hinged and make the apparatus readily accessible. It provides a compact shelter for the apparatus as well as a seat for the tower observer. The set sits on top of this box beneath the window sill and the microphone hangs above it between the windows.

Since regular tower observers, without radio training, operate these stations, ease of operation and reliability are prerequisites. Our relatively simple circuit has proven very saisfactory in these respects and possesses the additional advantages of low construction and operating costs.

A complete installation including gas engine charging unit, costs in the neighborhood of $\$ 200.00$ for parts. The parts are purchased and sets built up by the staff of the Radio Service during the winter months and they supervise installations and the work of keeping the sets in good operating shape in the field during the summer.

The right kind of organization and training to get the most use of radio in fire protection work will require a good deal of thought and trial, but should result in more systematized lookout routine and better trained observers. 
One limitation radio has, at the present stage of its development at least, is that the towerman cannot be as loudly and dependably signalled when wanted as by telephone. Where telephone is used an instrument can be installed in the towerman's living quarters as well as in the tower and an extension bell can be set up outside to summon him if at work nearby. To get good results with radio a system of time schedule must be established at which times the observer must be at his instrument in the tower to listen-in and to send messages. This means that in hazardous weather, at least, he must be fairly constantly in his tower and can have little time for work elsewhere in the immediate vicinity. While this may result in a poorly kept trail and tower surroundings, it does keep the towerman alert and on the job and our experience has been that in general where radio is used more reliable detection results from the fact that the observer must be more constantly in his tow. er. It might be said here that in the minds of most men an observer's job is a lonely and monotonous one. It calls for dependability, fortitude and intelligence and a really good observer is a rare find. With the expansion of the tower system of detection and the use of radio, better facilities for training should be established and in lonely and isolated stations at least there should be two men stationed. For reasons of economy, it is seldom done, but in a properly organized protection system it should not be overlooked.

As I am most conversant with the use of radio in Sudbury District, and as I believe they are the same as in general practice in Ontario, the methods used here can be used for illustration.

There are this year twenty-eight sets in the district and one portable set made up by one of our towermen, as well as five new type portables. These are distributed throughout seven Chief Ranger Divisions ranging from two to eight per division, some having telephone communication already developed more than others. There are forty towers in all, some with telephone communication only, some with radio only and the remainder with both telephone and radio. For the past two seasons two outlying Divisional Headquarters have been linked up with our Air Base by means of more powerful TR.200 sets rented from a commercial firm, but this year such communication is being carried out by further extension of the five meter sets to intervening towers.

At the end of the fire ranging season all sets, including charging units and aerials are removed from the towers. The transmitting and receiving sets are sent to Toronto for overhaul by the Provincial Radio Service and for installation of any improvements that have been made. Batteries, charging sets and aerials are overhauled, and put in repair at Sudbury by district radio and telephone man. In Spring the equipment is shipped out and installations made by the district man with the assistance of one or two men from our Radio Service and one of these men remains for the season to assist in keeping the sets in working order. Towermen in all cases have been chosen from the fire ranging staff and have had no previous training in radio. Some have shown remarkable adaptability and have even taken correspondence courses in radio work to make them more efficient. One-as mentioned-has so improved himself that he built a set which last year gave splendid service in keeping a trail cutting gang in constant touch with towers and on three occasions gave them word to proceed to fires which they were able to extinguish quickly and from which they were able to report progress. At first, among 
the older men particularly there was reluctance towards "tinkering" with the new apparatus and towards broadcasting, but this soon passed and some of the older men are among the most enthusiastic radio users. As a matter of fact there is little more to their use than there is to operating a receiving set in one's home, other than operating the gas engine for charging the batteries. As with the receiving set at home when "something goes wrong" the "radio man" is called in to make repairs or adjustments - and it happens about as often. Most of our troubles with keeping sets in the field in repair have been from parts broken or put out of adjustment during transport through the bush or in being hoisted into the towers. These troubles are largely overcome by creating special packing gear and containers to fit the different units and by providing every tower with a good set of ropes and pulleys and properly erected hoisting gear. A good kit of primary tools such as spanners, screw. drivers, pliers and hammer are supplied so that obvious repairs can be made.

Within each district the tower sets are "grouped" according to their location in relation to a "key" tower and to the headquarters with which they work. A group is usually formed of the towers within a Chief Ranger's Division and may range from one to eight or nine towers. The "key" tower must have good reception, and must be connected to headquarters by a reliable telephone system. Each of these groups is assigned a frequency band within the range of the general band of from $4 \frac{1}{2}$ to 7 meters which has been assigned to the Province. These group bands are distributed in such a way that there will not be interference with other groups when broadcasting at the same time. The range of tower sets, unless under exceptional conditions, is in the neighborhood of fifty miles, so that groups one hundred miles away would rarely be interfered with even if on the same frequency. A fairly large number of adjacent groups can, therefore, be arranged within the general band without interference.

Schedules for conversation are, in times of moderate haard, usually one hour spart, or in times of very low hazard may be only twice or thrice daily. In times of high hazard they are stepped up usually to every quarter hour. They are arranged for by mutual agreement between groups by the Chief Fire Ranger or some other authorized official. At night or during a lightning storm, plugs of aerial lead-ins are removed from the set and plugged in to grounded jacks.

At the time scheduled for conversation all towermen in the group should be listening-in with sets tuned to receive a call from the "key" tower. The "key" towerman with his radio set for transmitting, calls on a tower by name and switches over to receive. If he receives a reply he completes his business with him and goes on in rotation to the other towers in his group. If he receives no reply he takes up conversation with the next tower, returning when he has completed the round to the tower which has not answered. When the "key" man has received all reports and has transmitted what messages he may have to towermen he calls headquarters by telephone and gives them any relevant information. If further information is requested by Headquarters or if they have further messages to transmit through the towers, this business is now taken up and is continued until the "key" man announces that conversation is ended and has set the time for next call. It is very essential that conversation time be kept to the minimum, especially when fires are burning. 
The group system with key tower has been tried as one way of accomplishing this and is an improvement on indiscriminate inter-tower conversation.

A considerable amount of experimental work has been done with portable sets in boats and trucks and with crews in the woods working on fires or improvements. As these sets are necessarily on the ground and the five meter tower type sets depend on partial visibility, dependable reception cannot be had for long distances at all times. For this reason a model using $60-80$ meter wave length has been tried as well as the five meter type and this year there will be several of these sets in use.

These sets no doubt have their place and use as in communicating between a headquarters and a patrol boat on a large waterway or with trucks where there is a network of roads, but as they cannot work in with the general setup of the tower system it would seem that their use will be limited to special locations.

Excellent results have been had by using an ordinary tower set with a work crew in the woods. In areas where there is a full complement of towers averaging twenty-five to thirty miles apart there are few places where a fire crew with a five meter set cannot be in communication with a tower and thus to headquarters. Such a set-up would be extremely practical and there is no reason why it could not be extended to contact isolated rangers and to equip aeroplanes 'with special five meter sets. The conditions which have led to the adoption of radio in the more isolated sections of the forested areas of Ontario in preference to telephone lines will illustrate the fundamental considerations which should determine the selection of one or the other of these two methods of communication.

Land lines have their greatest expense in the construction and maintenance of the line itself and must therefore have fairly numerous outlets-telephones -if line cost is to be justified. Also land lines are very largely fixed. Radio in contrast has its cost concentrated in the instruments and therefore should be used to cover long distances where few outlets are required. It also has the advantage of portability.

It may be safely stated, I think, as a general principle, that where there are railroads or used roads which offer a cleared right-of-way for reasonably cheap building and maintenance and from which headquarters ranger stations and towers can be reached, telephone lines are to be preferred to radio and their cost is justified. Where such conditions exist lines should be of standard pole construction with metallic circuit.

It is considered to be sound policy that telephone communication should be the aim in joining up District, Divisional and Deputy Chief Headquarters if it can be done under conditions laid down in the preceding paragraph. Of course as many intermediate stations as possible should be included. The telephone offers a better form of communication for lengthy discussions involving more or less intricate detail such as is often needed between head. quarters and it should be the aim to relieve the radio system of this as much as possible.

For communication with isolated posts, towers, fire fighting and work crews, boats and trucks, where portability and low cost are prime factors, radio is now not only practical but preferable and can be ranked with the lookout tower and the telephone as No. $1 \mathrm{G}$ men in fighting forest fures. 